\title{
The construction technology and finite element analysis of the whole lifting of large grid
}

\author{
Deyuan Deng ${ }^{1, *}$, Weixiong Zhang ${ }^{2}$, Zixuan $\mathrm{Li}^{1}$, Guangjun $\mathrm{Li}^{2}$, TianFang Mo ${ }^{2}$, Zhou Chen ${ }^{3}$, and Hanwen $\mathrm{Lu}^{3}$ \\ ${ }^{1}$ China Construction Steel Engineering Co., Ltd, Shenzhen, Guangdong, 518054, China \\ ${ }^{2}$ China Construction Fourth Engineering Division Corp. Ltd, Guangzhou, Guangdong, 510665, China \\ ${ }^{3}$ Foshan University, Foshan, Guangdong, 528225, China
}

\begin{abstract}
Taking a large grid frame in a maintenance hangar of Guangzhou Baiyun Airport as the research object, the construction steps of lifting the grid structure are briefly described, and the static mechanical characteristics, dynamic mechanical characteristics and stability of the large grid frame were studied by using Midas/Civil finite element analysis software, which meets the design and the practical application requirements. Since its first six orders safety factors are greater than 4 . The stress state of the nodes at the important supports in the grid is mainly controlled by axial force.
\end{abstract}

\section{Introduction}

With the improvement of China's comprehensive national strength and the development of economy, steel structure has gradually become one of the main structures in construction projects, and has been applied in workshops, high-rise buildings, super high-rise buildings, airport terminals and aircraft maintenance depots and other fields.

In recent years, the span of the traditional building structure, such as the reinforced concrete frame structure, is often limited by the distance between columns and grids. At the same time, the larger self-weight of the concrete structure also puts forward higher bearing capacity requirements for the substructure and foundation, which is unfavourable to the overall design of the project. [1] At the same time, the grid structure because of its light weight, flexible design and other advantages, in the choice of large-span space structure form has been favoured by designers.

The application of grid structure has been widely studied by scholars at home and abroad. Ji [2] based on a long-span space grid structure engineering, for the space of large-span space truss structure in the auxiliary support to dismantle the bar stress conditions are studied, and analyses the auxiliary support in the demolition of before and after the demolition of security. Fu [[3] believes that aiming at the defects of space grid structure, is to keep the space grid structure can long-term reliability and safety of one of the necessary measures. Zhao et al. [4], based on the construction practice of a large-area and large-span structural workshop, introduced a series of construction difficulties such as its overall lifting, lifting platform design and lifting point setting. Sun [5] for Huo Qiu sports center stadium steel structure roof in the difficulty in the unloading process, put forward a kind of support for the more practical unloading method, and through the finite element method to ensure that the large span roof when unloading the feasibility and safety of steel structure.

At present, there are many researches on the grid structure in the industry, but few researches on the construction analysis and finite element analysis of the large-span space grid structure. Therefore, this paper takes this as the starting point and takes the No.18 maintenance hangar project of the third phase of GAMECO aircraft maintenance facility in Guangzhou Baiyun Airport of China Southern Airlines as the background to introduce the construction scheme of the large-scale grid frame upgrading and carry out finite element calculation and analysis on the overall force of the grid frame during operation.

\section{Project summaries}

The project is located at the east side of Konggang North Road, the intersection of Konggang North Road and Konggang North Road, Guangzhou Airport Economic Zone, Guangzhou, Guangzhou, and the west side of the maintenance base of Guangzhou Aircraft Maintenance Engineering Co., Ltd., Guangzhou New Baiyun International Airport. The plane size of the hangar hall is $334 \mathrm{~m} \times 107.65 \mathrm{~m}$. The structure of the hangar hall adopts the combination of grid frame and truss structure. The grid frame adopts the welded hollow ball and rod structure, and the structure is two-storey diagonal fourangle cone grid frame. The opening side of the hangar gate is equipped with two trusses of steel structure. The upper and lower chord sections are welded box sections, and the belly and middle chord members are round pipe members. The schematic diagram of the main steel structure is shown in Figure 1.

*Corresponding author's e-mail: dengdeyuan@cscec.com 

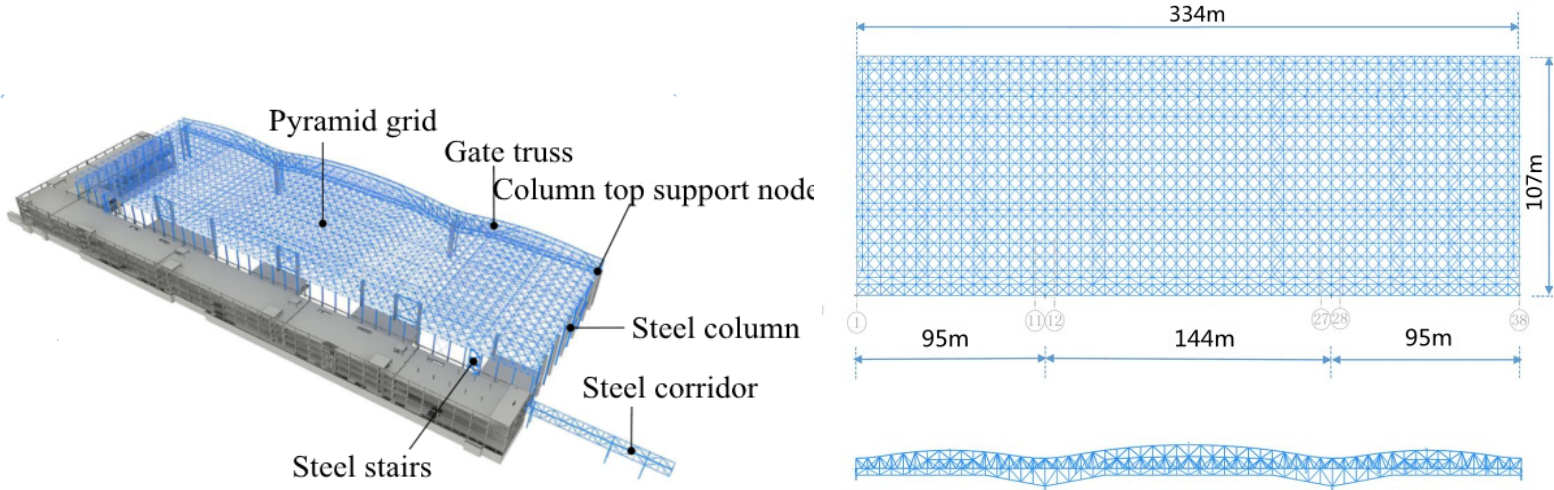

Figure 1. Diagram of main steel structure.

\section{Construction plan}

The steel structure grid has the advantages of high installation height, large vertical and horizontal span, numerous structural bars and large dead weight. If the conventional high-altitude bulk packing scheme is adopted, a large number of high-altitude scaffolds need to be set up, which is difficult to construct, and will have a great impact on the construction period of the whole project, and the economic efficiency of the scheme is poor. If large-scale crane is used to lift the whole

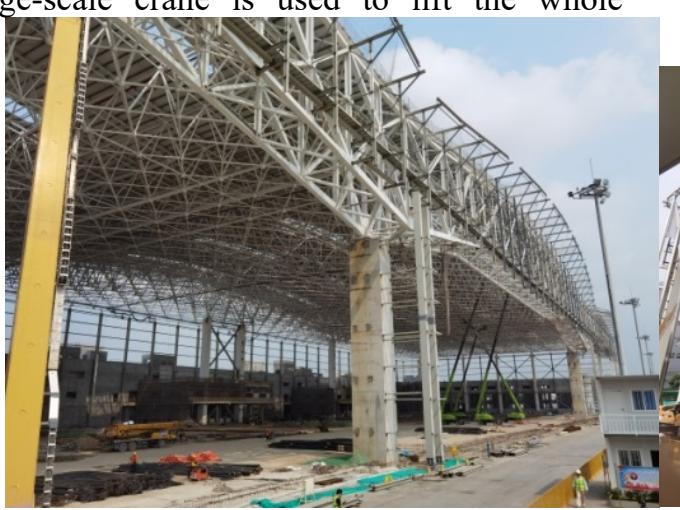

Figure 2. The third phase of GAMECO aircraft maintenance facility.

The main process of grid lifting in this project is shown in Figure 3, and the specific operations are as follows:

(1) Assemble the grid structure on the ground, set the lifting platform on the top of the column, install the lifting equipment and steel strand, and debug the hydraulic system.

(2) After the assembly of the grid frame is completed, the pre-lifting shall be carried out after a comprehensive inspection and acceptance. After confirming that there is no abnormal situation, the hoist shall be mechanically locked and stand for about 12 hours.

(3) Carry out a comprehensive inspection, measure the deformation of the grid and the settlement of the

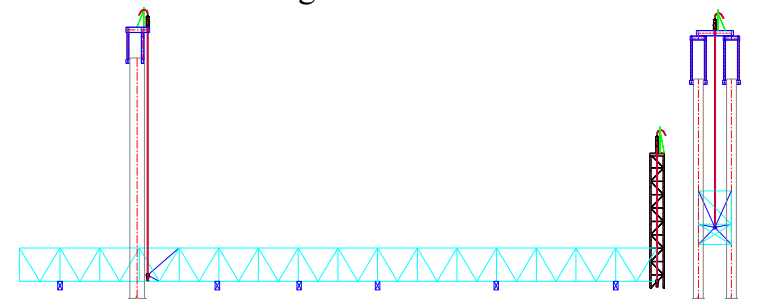

(a) Structure assembly and equipment installation installation, large tonnage crane is needed, and there are higher requirements for ground foundation, and there are certain safety risks.

According to the experience of similar projects [6], if the steel structure is assembled on the ground as a whole, the "super large hydraulic synchronous lifting construction technology" is used to lift it in place once, and then the top part of the column is reserved for the installation of the rear rod, the installation and construction difficulty will be greatly reduced. The hangar scene diagram is shown in Figure 2. column foundation, and carry out the overall lifting operation of the grid after confirming that everything is normal.

(4) Remove the temporary lifting frame and continue the overall lifting operation.

(5) the grid is lifted to the design position, and the installation of the grid inserts and supplementary rods is carried out.

(6) After the installation of the embedding rod of the grid frame is completed and the acceptance is qualified, the hoist shall be unloaded, the lifting equipment and temporary structure shall be dismantled, and the lifting operation shall be completed.

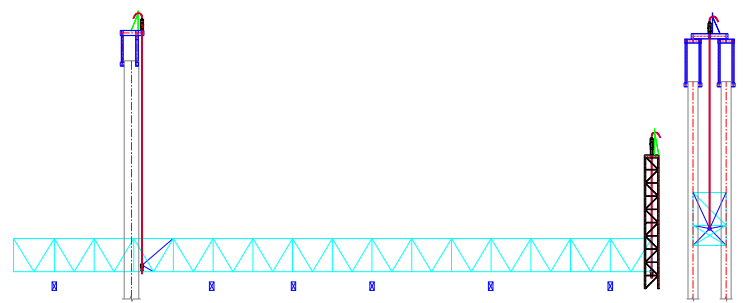

(b) Pre-lifted 


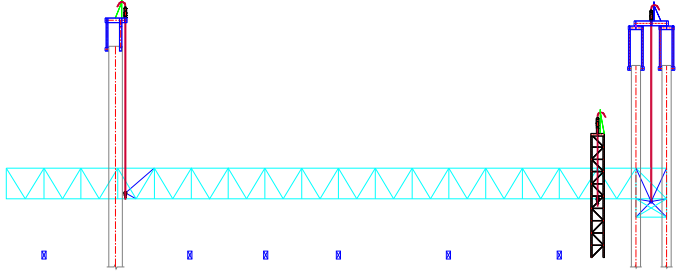

(c) Overall lifting

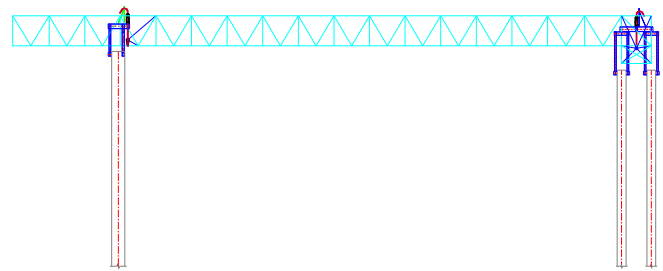

(e) Install the mesh frame insert repair rod

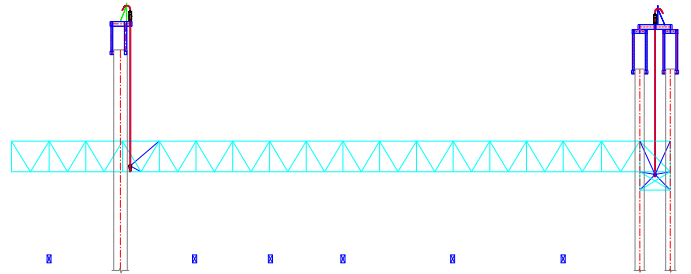

(d) Lifting continue after removal of temporary hoisting frame

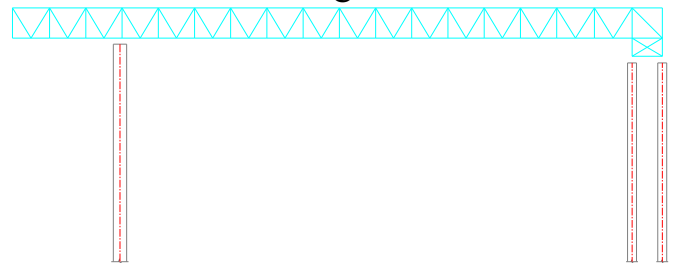

(f) Uninstall

Figure 3. Main flow chart of lifting.

\section{Finite element analysis}

The stress condition of large space grids during operation is worth paying attention to. Therefore, this paper starts from the overall force of the grid, carries on the static analysis and stability analysis to the large grid, and studies its weak and important structural parts. In this paper, Midas/Civil finite element analysis software is used to model and analyse the large grid.

Considering that the joints of all the rods are welded as a whole in practice, the stiffness of the joints is very large and it is not an ideal hinge, so it is considered that the grid frame is just connected as a whole. The bending moment will be transferred as soon as the connection is made, so the beam element is used to model the grid. The model diagram is shown in Figure 4.

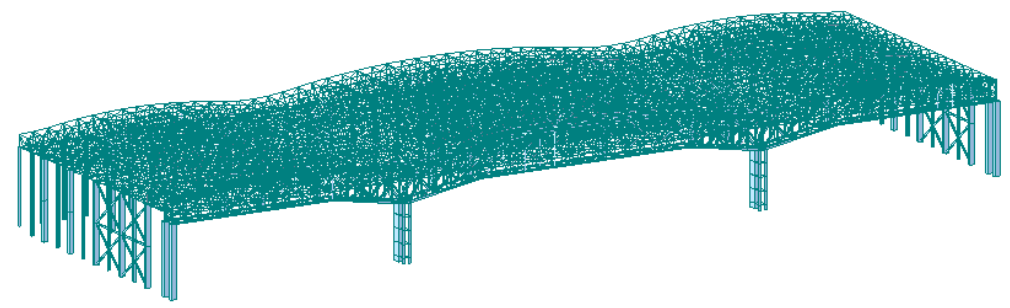

Figure 4. Finite element model diagram of grid.

The columns are rigidly connected with the grid, and the boundary conditions are set below the columns, and the boundary conditions are consolidation. In order to facilitate the analysis, the load only considers the selfweight effect of the grid.

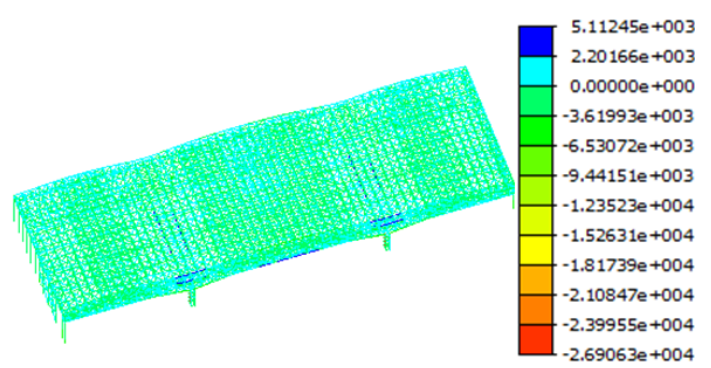

(a) Axial force $(\mathrm{kN})$

\subsection{Static mechanical properties}

After setting, the overall internal force and stress force of the grid can be calculated by running, as shown in Figure. 5-6.

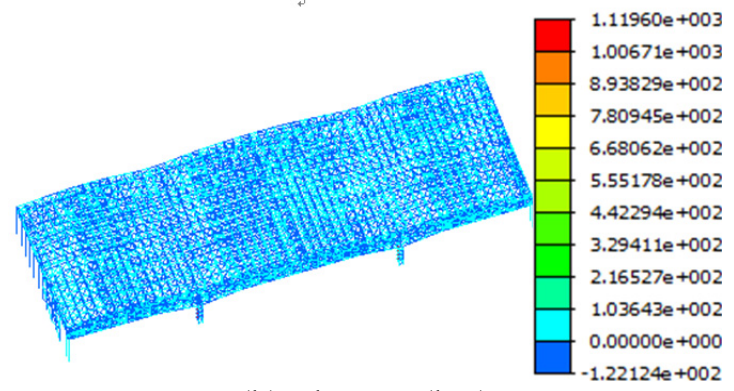

(b) Shear-y $(\mathrm{kN})$ 


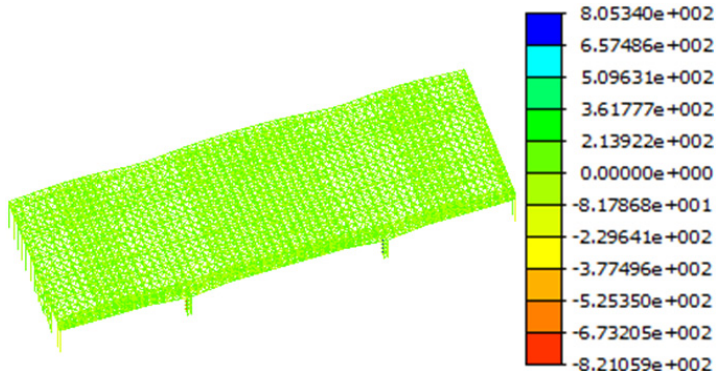

(c) Shear-z $(\mathrm{kN})$

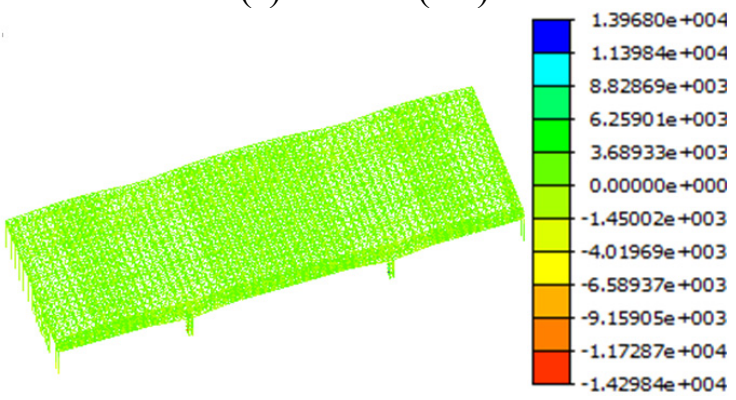

(e) Bending moment-y (kN.m)

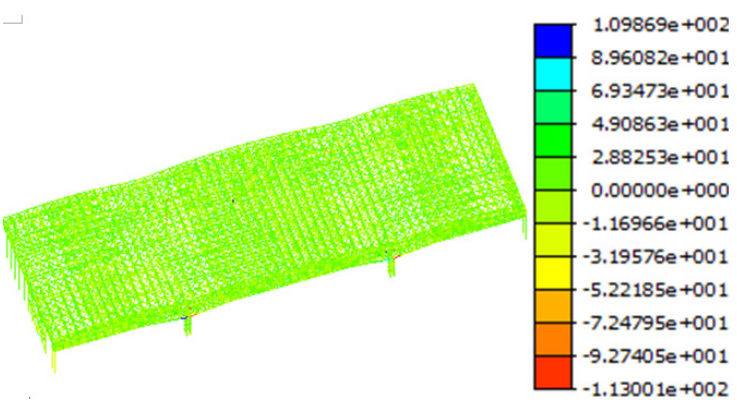

(d) Torque (kN.m)

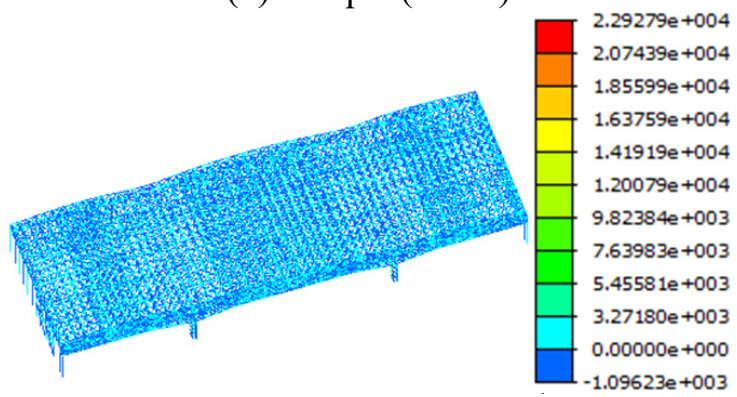

(f) Bending moment-z (kN.m)

Figure 5. The overall internal diagram of the grid.

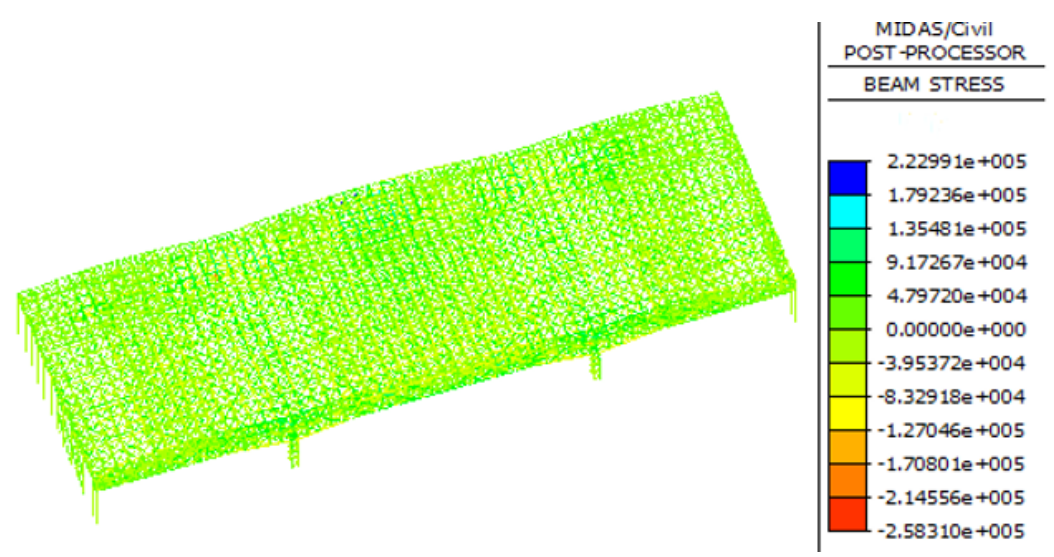

Figure 6. The overall stress diagram of the grid (Unit: MPa).

According to the analysis in Figure 4, on the whole, the axial force distribution of each bar is relatively uniform and is mainly under compression. The axial force of the vast majority of bars is no more than $14000 \mathrm{kN}$ and no less than $-8900 \mathrm{kN}$. A few bars located above the column will show a state of tension, and the tension is not large relative to the pressure. Other internal forces are also relatively uniform, and there are no excessive internal forces.

According to the analysis in Figure 5, the stress of each member conforms to the stress state. The upper chord of the middle span mainly presents compressive stress, the lower chord mainly presents tensile stress, the upper chord of the column mainly presents tensile stress, and the lower chord mainly presents compressive stress. The stress state of each bar is good, and no bar enters the yield stage due to excessive stress. The stress at the joint is mainly compressive stress and does not exceed the yield strength of the bar material.

The more important node of the grid is studied, which is located at the support above the concrete column. Five of the joints intersecting each other are numbered 1-5 from left to right, and the internal forces of the five joints are read and summarized, as shown in Table 1:

Table 1. The sum of the internal forces at the joint

\begin{tabular}{|c|c|c|c|}
\hline Number & Fx:Axial force $(\mathrm{kN})$ & Fy: Shear $-\mathrm{y}(\mathrm{kN})$ & Fz :Shear $-\mathrm{z}(\mathrm{kN})$ \\
\hline 1 & -11165 & 43 & 185 \\
\hline 2 & -14975 & 40 & 108 \\
\hline 3 & -9060 & 39 & -8 \\
\hline 4 & -17044 & -52 & -119 \\
\hline
\end{tabular}




\begin{tabular}{|c|c|c|c|}
\hline 5 & -10838 & -101 & -217 \\
\hline Number & Mx: Torque $\left(\mathrm{kN}^{*} \mathrm{~m}\right)$ & My Bending moment $-\mathrm{y}\left(\mathrm{kN}^{*} \mathrm{~m}\right)$ & Mz Bending moment -z $\left(\mathrm{kN}^{*} \mathrm{~m}\right)$ \\
\hline 1 & 43 & -1066 & -323 \\
\hline 2 & 101 & -642 & -100 \\
\hline 3 & -6 & -40 & 287 \\
\hline 4 & -155 & -614 & -120 \\
\hline 5 & -70 & -1079 & -493 \\
\hline
\end{tabular}

As can be seen from the above table, the five bar members in the node are all affected by the joint action of axial force, bending moment, shear force and torque, but on the whole axial force plays a dominant role, while bending moment, shear force and torque have little influence.

\subsection{Dynamic characteristics and stability analysis}

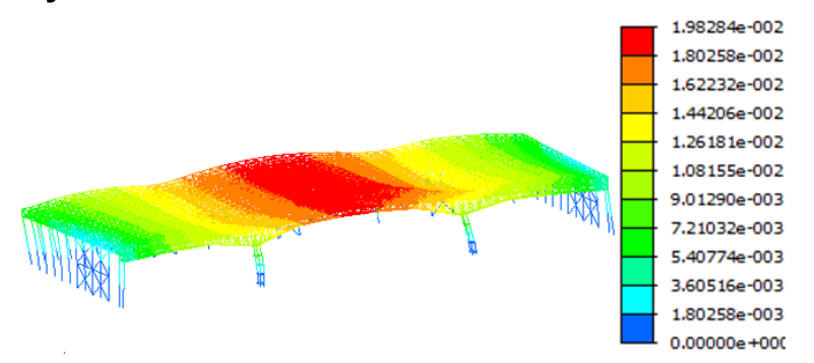

For the structure, its dynamic and mechanical properties are controlled by the natural frequencies and modes of the first several modes of the structure [7]. In this paper, the Lanczos iterative method of Midas/Civil was used to solve the natural vibration characteristics of the first six orders of the structure. The natural vibration frequency and mode characteristics are shown in Table 2. In view of the limited space, only the first three order modal diagrams of the structure are listed, as shown in Figure 7.

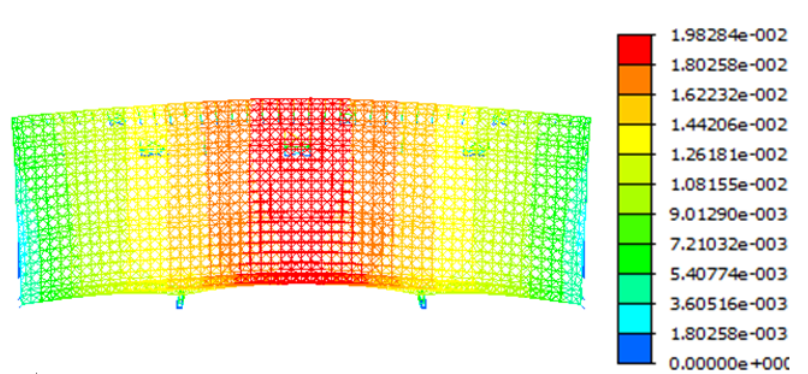

(a) Mode 1

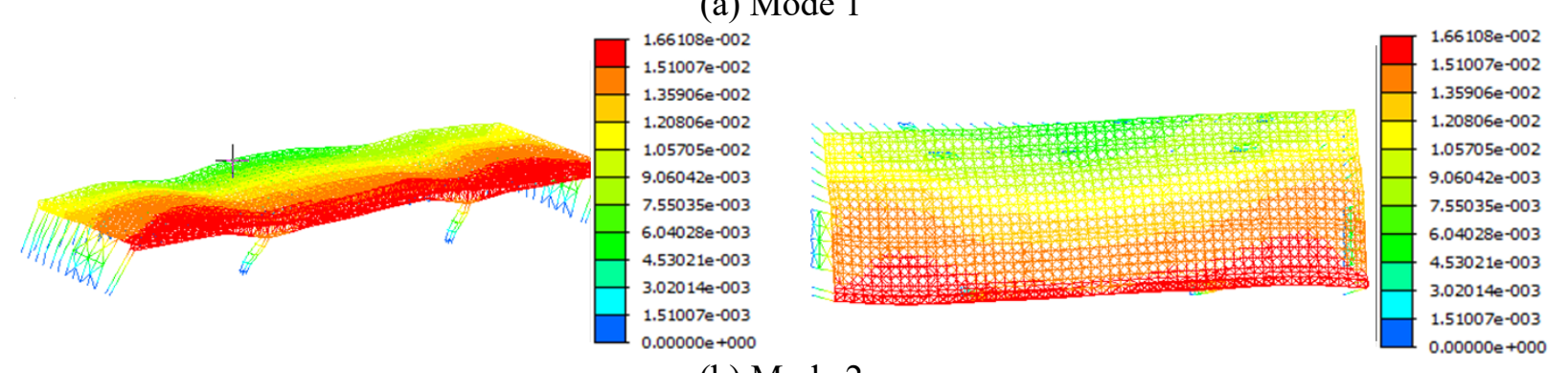

(b) Mode 2

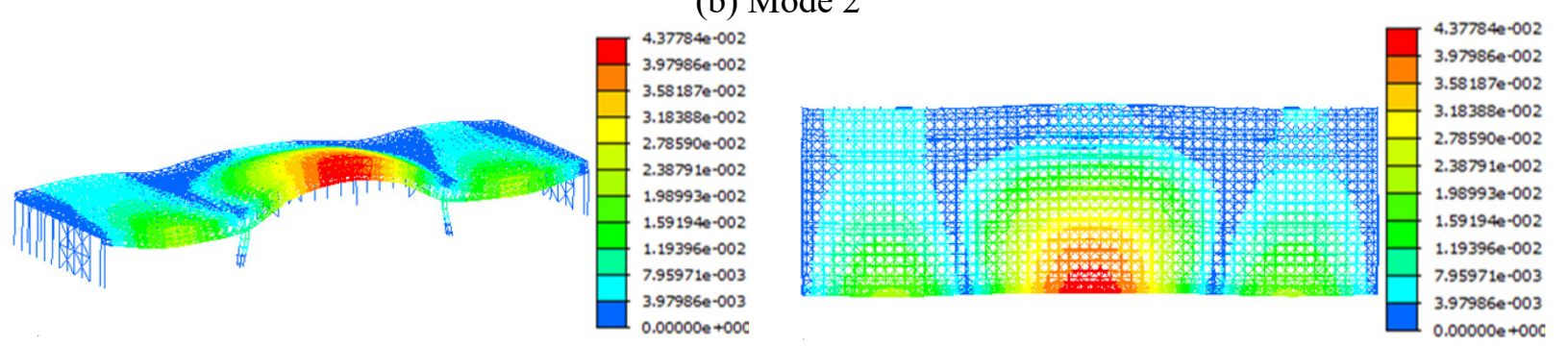

(c) Mode 3

Figure 7. The overall stress diagram of the grid (Unit: MPa).

As a large structure, the linear elastic stability coefficient of the grid is complex. Therefore, this paper adopts the linear elastic stability theory of the first kind whether the stability of the first six order buckling modes meets the requirements (stability safety factor $K>4$ ). The $\mathrm{K}$ values of the first 6 orders are shown in Table 2 . to calculate the stability safety factor $\mathrm{K}$, and analyses

Table 2. The natural vibration frequency, mode characteristics and $\mathrm{K}$ of the first six orders

\begin{tabular}{|c|c|c|c|}
\hline Order & Natural vibration frequency $(\mathrm{Hz})$ & Mode characteristics & $\mathrm{K}$ \\
\hline 1 & 1.149 & Transverse symmetric bending & 8.886 \\
\hline 2 & 1.435 & Vertical bending & 9.609 \\
\hline 3 & 1.781 & Longitudinal symmetric bending & 9.861 \\
\hline 4 & 1.827 & Transverse antisymmetric bending & 10.531 \\
\hline 5 & 2.230 & Bulge on the right side & 10.951 \\
\hline
\end{tabular}




\begin{tabular}{|c|c|c|c|}
\hline 6 & 2.235 & Bulge on the left side & 11.091 \\
\hline
\end{tabular}

From this analysis, it can be concluded that the safety factor $\mathrm{K}$ of each order is greater than 4 , satisfying the stability requirements.

\section{Conclusions}

Through finite element modelling analysis of the grid, the following conclusions can be drawn:

1. The force of the grid frame is uniform and reasonable, which meets the design requirements and meets the practical application requirements;

2. The stress state of the nodes at the important supports in the grid is mainly controlled by the axial force. And the overall stress state of the grid is controlled by the node at the support. Therefore, the optimization of the grid should start from the important nodes, and the stress state of the important nodes should be calculated and analysed locally from the axial force.

3. The first six order safety factors of the large grid are all greater than 4 , so its stability meets the requirements.

\section{References}

1. Mao, Z. (2021) Design and Construction Points of Rectangular Square Pyramid Space Truss
Structure in Large Steel Structure Venue. Structure Construction, 43(01):34-36+42.

2. Ji, R., Lu, Y. (2008) Construction Safe Monitoring of Large-span Space Truss Structure. Foreign building materials technology, (01):101-103.

3. Fu, S. (2015) Evaluation of normal usage of a large span space grid structure. Building Materials and Decoration, 000(032):38-40.

4. Zhao, J., Wang, Y. (2011) Integral Lifting Construction Technology for the Long-span and Large-area Space Grid Structure in Some Project. Construction Technology, 40(09):65-68.

5. Sun, X., Niu, Z., Li, Z., Ding, S., Tie, L. (2018) Simulating analysis and monitoring of unloading process of large-span spatial structure. Building Structure, 48(11):70-77.

6. Qin, J., Yi, T., Wang, B. (2013) Large-scale grid block lifting construction technology. Coal engineering, S2:84-85.

7. Chen, Z., Chen, S., Deng, D., Yang, G., Lu, H., 2020. Study on the mechanical characteristics of arch rib of mid through tied arch bridge in different construction stages.In: Industrial Building Academic Exchange Conference. 